\title{
The association of glutathione-S-transferase gene polymorphisms (GSTM1, GSTT1, GSTP1) with idiopathic male infertility
}

\author{
Mohammad Reza Safarinejad, Nayyer Shafiei and Shiva Safarinejad
}

The effects of the GST genes (GSTM1, GSTT1 and GSTP1) on male factor infertility have not been well elucidated. A casecontrol study was performed to investigate the association between functionally important polymorphisms in GST genes and idiopathic male infertility. The study group consisted of 166 men suffering from idiopathic oligoasthenoteratozoospermia (OAT) and an equal number of age-matched healthy fertile male controls. Genomic DNA extracted from the peripheral blood, was analyzed by polymerase chain reaction (PCR) and restriction fragment length polymorphism (RFLP) methods. Multivariate regression analysis showed an increase in risk to infertility in the patients with null genotype of GSTM1 (OR: 2.18; $95 \% \mathrm{Cl}$ : 1.64-3.32; $P=0.001$ ) or GSTT1 (OR: $1.88 ; 95 \% \mathrm{Cl}: 1.12-2.52 ; P=0.04$ ). Our data further showed that combination of deletion genotypes of GST (GSTM1 and GSTT1) pose an even higher risk of infertility. In addition, GSTP1 wild-type genotype in combination with GSTM1 null or GSTT1 null genotype increased probability for infertility (OR: $2.47,95 \% \mathrm{Cl}: 1.46-4.17$ : and OR: $2.69,95 \% \mathrm{Cl}: 1.39-5.32$, respectively). Similarly a much higher risk for infertility was noted in the patients carrying a genotype combination of GSTM1 null, GSTT1 null and GSTP1 (lle/lle) (OR: $4.45 ; 95 \% \mathrm{Cl}: 1.59-12.24 ; P=0.002$ ). The variant genotypes of GSTP1 (Ile/Nal and Val/Val) resulted in a significant decreased risk to infertility in the cases (OR: $0.44 ; 95 \% \mathrm{Cl}$ : $0.29-0.78, P=0.004)$. These results support the hypothesis of increased risk of GSTM1 or GSTT1null genotypes for developing infertility, but the nondeletion GSTM1 and GSTT1genotypes emerged as protective factors.

Journal of Human Genetics (2010) 55, 565-570; doi:10.1038/jhg.2010.59; published online 27 May 2010

Keywords: genetic; glutathione-S-transferase (GST); infertility; male factor; polymorphism

\section{INTRODUCTION}

Infertility is a multifactorial disorder affecting one in ten couples, and in $50 \%$ of infertile couples, the male factor due to deteriorated semen quality is a major cause. ${ }^{1,2}$ In about $30 \%$ of infertile men seeking help for their problem, the etiology and pathogenesis are not yet known and their condition is considered idiopathic. ${ }^{3}$ Several studies over the past two decades have suggested that the quality and quantity of human semen is declining worldwide in industrialized countries, raising concern about male fertility in the future. ${ }^{4,5}$ Although exact possible causes are not yet understood clearly, interactions between genetic and environmental factors have been suggested to be implicated with deteriorated semen quality. 6,7 Damage to the genetic component of spermatozoa have a crucial role in a majority of cases where current investigations fail to detect the specific cause of male infertility. ${ }^{8}$ It has been shown that some genetic polymorphisms are associated with impaired spermatogenesis in infertile men with idiopathic oligoasthenoteratozoospermia. ${ }^{9}$ Indeed genetic causes are implicated for $60 \%$ of cases of idiopathic infertility. ${ }^{10}$ Xenobiotics comprise the majority of the environmental factors. ${ }^{11}$
Excessive reactive oxygen species (ROS) have been considered to be one of the major factors leading to an infertile status ${ }^{12}$ via oxidative DNA damages including base damage and DNA strand breaks. Glutathione-S-transferases (GST, EC 2.5.1.18) are a super-family of phase II antioxidant enzymes involved in the cellular detoxification of various physiological and xenobiotic substances. ${ }^{13}$ GSTs constitute the major defensive antioxidant system against oxidative stress by reducing ROS to less reactive metabolites. ${ }^{14}$ Polymorphisms in the GST gene may impair the ability of protection against oxidative stress and lead to the development of a wide range of diseases. ${ }^{15}$ Endogenous DNA fragmentation in human sperm (indicated by percentage of DNA fragmentation index) can be modulated by a polymorphism (deletion) in GSTM1. ${ }^{16}$

GSTs are currently categorized into eight separate classes, including alpha, mu, kappa, omega, pi, sigma, theta and zeta, that are encoded by GSTA, GSTM, GSTK, GSTO, GSTP, GSTS, GSTT and GSTZ genes, respectively. ${ }^{17,18}$ Three of the GST genes, GSTP1, GSTM1 and GSTT1, coding for GSTs enzymes in the mu, theta and pi classes, respectively, have been found to have functional polymorphisms that are frequently present in the general population. ${ }^{19}$ The polymorphism in the GSTT1

Urology and Nephrology Research center, Shahid Beheshti University (MC), Tehran, Iran

Correspondence: Professor MR Safarinejad, Urology and Nephrology Research Center, Shahid Beheshti University (MC), P0 Box 19395-1849, Tehran, Iran.

E-mail: safarinejad@unrc.ir

Received 12 March 2010; revised 29 April 2010; accepted 30 April 2010; published online 27 May 2010 
and GSTM1 gene loci is caused by a gene deletion and results in the virtual absence of enzyme activity, especially in individuals with deletion in both genes (null genotypes). ${ }^{20}$ Two genetic variants have been reported in GSTP1 gene, leading to isoleucine (Ile) to valine (Val) polymorphism at codon 105 and alanine to Val transition at codon 114, which leads to significant differences in catalytic activity. ${ }^{21}$

Inconsistent studies are available on the association of polymorphism in GSTM1, GSTT1 and GSTP1 genes and idiopathic male infertility. Aydemir et al. ${ }^{22}$ reported that in patients with idiopathic infertility, GSTM1 polymorphism might be an important source of variation in susceptibility of spermatozoa to oxidative damage. In a study conducted in Russian men, Polonikov et al. ${ }^{23}$ reported that the nondeletion genotype of the GSTT1 gene is strongly associated with the increased risk of idiopathic male infertility and asthenozoospermia. Wu et al. ${ }^{24}$ reported that there was no statistically significant association between GSTT1 null genotype and Chinese infertile patients with varicocele. In another study from China, GSTT1 null genotype was a predisposing risk factor for sporadic idiopathic azoospermia or oligospermia in northwestern China. ${ }^{25}$ Another study in Turkish infertile men found that GSTM1, CYP1A1 ${ }^{\star} 2 \mathrm{C}$ genotypes are associated with infertility. ${ }^{11}$ The available data are not conclusive and few studies appear to have addressed the issue of association of idiopathic male infertility with GST genes. The aim of this study was to identify potential associations between polymorphism in GST gene (GSTM1, GSTT1, GSTP1), and idiopathic male infertility in an urban Iranian population.

\section{MATERIALS AND METHODS}

\section{Studied populations}

A case-control study was conducted to examine the association of functionally important polymorphisms in GSTs (GSTM1, GSTT1 and GSTP1), with idiopathic male infertility. Infertile men (mean age $31.4 \pm 5.2$ years, range 25-40 years) with idiopathic oligoasthenoteratozoospermia ( $n=166)$ visiting our facility of Urology, included in the study. An equal number of fertile healthy men ( $n=166)$ (mean age $31.8 \pm 5.6$ years, range $25-42$ years) of the same ethnic group and drawn from the same geographical and linguistic lineage, and similar socioeconomic status were also recruited in the study and served as the controls. All of the participants were recruited during the period from October 2006 to June 2009. The study participants were recruited consecutively after screening for eligibility and meeting the study inclusion and exclusion criteria. Idiopathic oligoasthenoteratozoospermia was diagnosed on the basis of at least two semen analyses with sperm parameters below the cutoff levels accepted by World Health Organization (WHO, 1999) ${ }^{26}$ alongside with no known reason that could account for their infertility. The criteria for normal semen parameters were sperm density greater than $20 \times 10^{6} / \mathrm{ml}$, sperm motility greater than $50 \%$, normal morphology greater than $30 \%$ and/or semen volume greater than $2 \mathrm{ml}$. All men in the control group had fathered at least one child, and have had normal semen parameters according to WHO guidelines (WHO, 1999). Infertile subjects did not achieve a pregnancy after at least 2 years of unprotected intercourse with the same partner.

The protocol for research conformed to the guidelines of the Declaration of Helsinki: Ethical Principles for Medical Research Involving Human Subjects and was approved by the local Ethics Committee.

Informed consent was obtained from the study participants before the collection of blood samples and it was also ensured that the subject anonymity was preserved.

\section{Evaluations}

All of the participants were subjected to detailed history taking, physical examination, scrotal ultrasonography and laboratory investigations, including standard biochemistry and hematological laboratory tests, and measurement of serum testosterone, luteinizing hormone, follicle-stimulating hormone, prolactin, thyroid-stimulating hormone, and Inhibin B levels. The existence of varicocele was rolled out by scrotal-colored Doppler ultrasound examination. Testicular volume was measured using scrotal ultrasound with a volume of less than $12 \mathrm{ml}$ considered small. At least two semen analyses after 3 days of sexual abstinence were performed 4 weeks apart. Karyotype analysis and Y chromosome micro-deletion evaluation were performed with use of standard techniques. The mixed agglutination reaction test was also performed for the presence of antisperm antibodies.

The female partners were diagnosed fertile after thorough clinical and laboratory examinations included, physical examination; baseline body temperature; serum progesterone concentrations at days 21 and 25 of the cycle; karyotyping; serum chemistry, hematology and hormonal profile, including: follicle-stimulating hormone, luteinizing hormone, prolactin, thyroid-stimulating hormone, and thyroxine; immobilizing antibodies in serum; antiphospholipid and anticardiolipin antibodies; lupus anticoagulant; hysterosalpingography; and cervical cultures for Ureaplasma, Mycoplasma, Chlamydia and bacterial vaginosis as needed. Female partners with abnormal findings on hysterosalpingography underwent laparoscopy and/or hysteroscopy.

\section{Inclusion/exclusion criteria}

All the infertile subjects had a history of infertility for at least 2 years with no indication of hormonal, medical, or surgical causes for their infertility. Exclusion criteria included azoospermia; a history of epididymo-orchitis, prostatitis, genital trauma and testicular torsion; a testicular volume of less than $12 \mathrm{ml}$; inguinal or genital surgery; genital disease such as cryptorchidism, urinary tract infection or varicocele; abnormal hormonal profile; presence of any endocrinopathy; use of cytotoxic drugs, immunosuppressants, anticonvulsives, androgens or antiandrogens; $\mathrm{Y}$ chromosome microdeletions or karyotype abnormalities; leukocytospermia (more than $10^{6}$ white blood cells per ml), or positive mixed agglutination reaction test; tobacco use; and drug, alcohol or substance abuse. Patients were also excluded from analysis if they had concomitant medical problems known to be associated with decreased fertility; hepatobiliary disease; significant renal insufficiency; a body mass index of $30 \mathrm{~kg} \mathrm{~m}^{-2}$ or greater; and occupational and environmental exposures to potential reproductive toxins.

\section{Genotyping}

Genomic DNA was extracted from the peripheral blood of subjects using the QIAmp blood kit (Qiagen, Chatsworth, CA, USA) and according to the method described by Liu et al. ${ }^{27}$ For the GSTM1 gene, DNA samples were amplified with the primers: $5^{\prime}$-CTGCCCTACTTGATTGATGGG- $3^{\prime}$ and 5'-CTGGATTGTAGCAGATCATGC-3', using polymerase chain reaction (PCR). The paired primers for GSTT1 were: 5'-TTCCTTACTGGTCCTC ACATCTC- $3^{\prime}$ and 5'-TCACCGGATCATGGCCAGCA- $3^{\prime}$. Amplification of human $\beta$-globin (110 bp) with the primers $5^{\prime}$-ACACAACTGTGTTCAC TAGC- $3^{\prime}$ and $5^{\prime}$-CAACTTCATCCACGTTCACC- $3^{\prime}$ was used as an internal control. PCR was performed in a final volume of $50 \mu \mathrm{l}$, consisting of DNA (0.5- $\mu \mathrm{l})$, and a PCR buffer containing $200 \mathrm{ng}$ of the following primers: dNTP (0.2 mm each), $\mathrm{MgCl}_{2}(1.5 \mathrm{~mm}), \mathrm{KCL}$ (50 mm), Tris- $\mathrm{HCl}$ (10 mm, $\left.\mathrm{pH} 8.3\right)$, and $0.1 \%$ of bovine serum albumin. Reaction mixtures were heated at $94{ }^{\circ} \mathrm{C}$ for 5 min followed by 35 cycles of amplification as follows: a denaturing step at $94^{\circ} \mathrm{C}$ for $90 \mathrm{~s}$, an annealing step at $59^{\circ} \mathrm{C}$ for $1 \mathrm{~min}$, and final extension step at $72{ }^{\circ} \mathrm{C}$ for $1 \mathrm{~min}$. Reaction products were analyzed by $2 \%$ agarose gel. The fragment lengths of the PCR products were 273-bp for individuals with one or more GSTM1 alleles, and 480-bp for individuals with one or more GSTT1 alleles.

The GSTP1 genotype was also determined by the method of Liu et al. ${ }^{27}$ using a PCR-restriction fragment length polymorphism technique. An $177 \mathrm{bp}$ fragment of the GSTP1 gene containing Ile to Val substitution in exon 5 (codon 105) was amplified using the primer pair $5^{\prime}$-ACCCCAGGGCTCTATGGGAA-3' and $5^{\prime}$-TGAGGGCACAAGAAGCCCCT- 3 '. The amplification cycles included an initial denaturing at $94^{\circ} \mathrm{C}$ for $30 \mathrm{~s}$, followed by an annealing step at $61^{\circ} \mathrm{C}$ for $30 \mathrm{~s}$, and a final extension step at $72^{\circ} \mathrm{C}$ for $30 \mathrm{~s}$. The PCR products were then digested with Alw26I. Homozygous Ile/Ile individuals had a single fragment of 177-bp, and homozygous Val/Val individuals had both 92- and 85-bp fragments. The presence of all three fragments corresponded to heterozygous Ile/Val individuals. 


\section{Statistical analysis}

Results are expressed as mean \pm s.d. Desired power of the present study was set at $80 \%$ as analyzed by power genetic association analysis software (http:// dceg.cancer.gov/bb/tools/pga) at the level of significance $\alpha=0.05$. Infertile men and healthy fertile controls were compared for differences in demographic characteristics using the Student's $t$-test for continuous variables and the $\chi^{2}$-test

Table 1 Baseline demographics, serum hormones and semen parameters of study groups

\begin{tabular}{|c|c|c|c|}
\hline Characteristics & Patients $(n=166)$ & Controls $(\mathrm{n}=166)$ & $\mathrm{P}$-value \\
\hline Age (year) & $31.4 \pm 5.2$ & $31.8 \pm 5.6$ & NS \\
\hline Duration of marriage & $7.8 \pm 2.7$ & $7.5 \pm 2.4$ & NS \\
\hline Infertility duration (year) & $4.8 \pm 2.2$ & $4.6 \pm 2.5$ & NS \\
\hline BMI $\left(\mathrm{kg} \mathrm{m}^{-2}\right)$ & $26.7 \pm 2.6$ & $26.7 \pm 2.5$ & NS \\
\hline \multicolumn{4}{|l|}{ Occupational status No. (\%) } \\
\hline Employed & $145(87.3)$ & $146(88.0)$ & NS \\
\hline Unemployed & $21(12.7)$ & $20(12.0)$ & NS \\
\hline \multicolumn{4}{|l|}{ Educational level } \\
\hline None & 0 & 0 & - \\
\hline Primary school & $8(4.8)$ & $9(5.4)$ & NS \\
\hline High school & $105(63.3)$ & $103(62.0)$ & NS \\
\hline Graduate & $53(31.9)$ & $54(32.5)$ & NS \\
\hline \multicolumn{4}{|l|}{ Serum hormones } \\
\hline Testosterone (nmol $\mathrm{I}^{-1}$ ) & $15.4 \pm 4.8$ & $15.6 \pm 4.6$ & NS \\
\hline $\mathrm{LH}\left(\mathrm{IU} \mathrm{I}^{-1}\right)$ & $12.2 \pm 2.4$ & $12.4 \pm 2.2$ & NS \\
\hline FSH $\left(I U I^{-1}\right)$ & $16.8 \pm 4.2$ & $16.4 \pm 4.6$ & NS \\
\hline PRL (pmoll $\left.{ }^{-1}\right)$ & $363 \pm 117$ & $367 \pm 122$ & NS \\
\hline $\mathrm{TSH}\left(\mathrm{mlU} \mathrm{ml^{-1 } )}\right.$ & $1.7 \pm 0.7$ & $1.7 \pm 0.7$ & NS \\
\hline Inhibin $B\left(\mathrm{pg} \mathrm{ml}^{-1}\right)$ & $189.6 \pm 21.4$ & $186.8 \pm 22.6$ & NS \\
\hline \multicolumn{4}{|l|}{ Semen parameters } \\
\hline Ejaculate volume (ml) & $2.7 \pm 1.3$ & $2.8 \pm 1.4$ & NS \\
\hline Total sperm/ejaculate $\left(\times 10^{6}\right)$ & $46.7 \pm 11.8$ & $197.2 \pm 32.2$ & 0.001 \\
\hline Sperm density $\left(\times 10^{6} / \mathrm{ml}\right)$ & $21.4 \pm 4.2$ & $70.8 \pm 16.6$ & 0.001 \\
\hline Motility (\% motile) & $24.8 \pm 2.4$ & $58.8 \pm 4.6$ & 0.001 \\
\hline Morphology (\% normal) & $17.6 \pm 4.2$ & $62.4 \pm 4.2$ & 0.001 \\
\hline
\end{tabular}

Abbreviations: BMI, body mass index; FSH, follicle stimulating hormone; LH, luteinizing hormone; NS, not significant; PRL, prolactin; TSH, thyroid stimulating hormone. for discrete variables. Odds ratios (ORs) and 95\% confidence intervals (CI) were calculated to measure the risk associated with variant genotypes by unconditional logistic regression method. Tests for Hardy-Weinberg equilibrium were conducted by $\chi^{2}$-test. The $\chi^{2}$ and Fisher's exact tests were performed to compare genotype frequencies between patients and controls. Correlation between two parameters was determined by Pearson's correlation coefficient $(r)$. A $P$-value less than 0.05 was considered statistically significant. The data were analyzed using the Statistical Package for Social Sciences (SPSS) software (version 16.0; SPSS Inc., Chicago, IL, USA).

\section{RESULTS}

The distribution of selected demographic and clinical characteristics in infertile patients and controls are shown in Table 1. Mean age ( \pm s.d.) was $31.4 \pm 5.2$ years among cases, age range 25-40 years, and $31.8 \pm 5.6$ years among controls, age range $25-42$ years $(P=0.1)$. No significant difference in the demographic characteristics was observed between cases and controls. The genotype distributions in the controls and patients were in agreement with the Hardy-Weinberg equilibrium ( $P=0.512, P=0.668$, respectively).

The distributions of GSTM1, GSTP1 and GSTT1 genotypes in cases and controls are shown in Table 2.

The frequency of null genotype of GSTM1 was significantly higher in patients (44\%) when compared with the cases $(27.7 \%)$ resulting in significant association between idiopathic male infertility and GSTM1 null genotype (adjusted OR: 2.18; 95\% CI: 1.64-3.32; $P=0.001$ ). Similarly the GSTT1 null genotype was also found to be prevalent in the infertile men, which significantly increased the risk to infertility (OR: $1.88 ; 95 \%$ CI: $1.12-2.52 ; P=0.04$ ). This increase in risk persisted even when the data was adjusted for age, duration of infertility, body mass index and occupational status, in multivariate logistic regression analysis (GSTM1, OR: 2.04; 95\% CI: 1.51-3.12; GSTT1, OR: 1.42; 95\% CI: 1.22-2.18, after adjusting). The frequency of the Ile/Ile genotype of GSTP1 was found to be higher in cases $(61.5 \%)$ when compared with the controls $(51.8 \%)$. As the frequency of the homozygous mutant $(\mathrm{Val} / \mathrm{Val})$ genotype of GSTP1 was very rare both in the cases $(3 \%)$ or the controls $(2.4 \%)$, the heterozygous and homozygous mutant genotypes were combined together and are referred to as variant genotypes (Ile/Val+Val/Val) of GSTP1. The frequency of the variant genotypes of GSTP1 (Ile/Val and Val/Val) was found to be higher in controls $(48.2 \%)$ when compared with the cases $(38.6 \%)$, and resulted in a significant decreased risk to infertility in the cases

Table 2 Distribution of GSTM1, GSTT1 and GSTP1 genotypes among infertile patients and controls

\begin{tabular}{|c|c|c|c|c|c|c|}
\hline Genotype and allele frequency & Control $(\mathrm{N}=166)$ & Cases $(\mathrm{N}=166)$ & Crude OR (95\% Cl) & $\mathrm{P}$-value & Adjusted OR $(95 \% \mathrm{Cl})^{\mathrm{a}}$ & P-value \\
\hline \multicolumn{7}{|l|}{ GSTM1 } \\
\hline Present & $120(72.3 \%)$ & $93(56.0 \%)$ & 1.0 (referent) & & & \\
\hline Null & $46(27.7 \%)$ & $73(44.0 \%)$ & $2.18(1.64-3.32)$ & 0.001 & $2.04(1.51-3.12)$ & 0.001 \\
\hline \multicolumn{7}{|l|}{ GSTT1 } \\
\hline Present & $134(80.7 \%)$ & $119(71.7 \%)$ & 1.0 (referent) & & & \\
\hline Null & 32 (19.3\%) & $47(28.3 \%)$ & $1.88(1.12-2.52)$ & 0.04 & $1.42(1.22-2.18)$ & 0.04 \\
\hline \multicolumn{7}{|l|}{ GSTP1 } \\
\hline Ile/lle & $86(51.8 \%)$ & 102 (61.5\%) & 1.0 (referent) & & & \\
\hline Ile/Nal & $76(45.8 \%)$ & 59 (35.5\%) & $0.71(0.42-1.06)$ & 0.08 & $0.42(0.22-0.78)$ & 0.001 \\
\hline Val/Val & $4(2.4 \%)$ & $5(3.0 \%)$ & $1.22(0.34-4.56)$ & 1.0 & $1.74(0.39-8.7)$ & 0.47 \\
\hline Ile/Nal or $\mathrm{Val} / \mathrm{Val}$ & $80(48.2 \%)$ & $64(38.6 \%)$ & $0.72(0.44-1.05)$ & 0.12 & $0.44(0.29-0.78)$ & 0.004 \\
\hline
\end{tabular}

Abbreviations: $\mathrm{Cl}$, confidence interval; GST, glutathione-S-transferase; OR, odds ratio.

aAdjusted OR: adjusted in multivariate logistic regression models including age, duration of infertility, body mass index, occupational status and GST genotypes. 
(adjusted OR: 0.44; 95\% CI: $0.29-0.78, P=0.004)$. When the genotypes of GSTM1and GSTT1 were combined, three genetic combinations were practical; (1) carriers of functional gene (GSTM1 and GSTT1), (2) carriers of either GSTM1 or GSTT1 as functional genotype and, (3) carriers for both the null genotypes.

About $33 \%$ of the infertile patients and $30 \%$ of controls carried the combination of null genotype of both GSTM1 and GSTT1, which increased the risk to 1.44 -fold (adjusted OR: 1.43 ; 95\% CI: 0.88-2.24) though not significant in the cases carrying both the null genotypes $(P=0.15)$.The risk associated with these variant genotypes was found to be further increased (approximately 3-fold) in cases carried both the null genotypes of GSTM1 and GSTT1 (adjusted OR: 2.92; 95\% CI:1.57-5.54; $P=0.0007)$.

When combinations of GSTM1 and GSTP1 were studied, the frequency of GSTM1+GSTP1 (Ile/Val or Val/Val) in infertile patients was 40 of $166(24.1 \%)$, which was lower than in control subjects (55 of $166,33.1 \%)$. This difference did not reach statistical significance $(P=0.06)$. Regarding the combination of GSTM1 null genotype with GSTP1 (Ile/Ile), distribution of the patients with null GSTM1 genotype+GSTP1 (Ile/Ile) polymorphisms was found to be higher $(27.7 \%$ ) as compared with the controls (13.3\%), which resulted in significant increase in infertility risk (adjusted OR: 2.47; 95\% CI: 1.46-4.17; $P=0.0006$ ) (Table 3).
Similarly, when genotype combinations of null GSTT1 genotype and GSTP1 (Ile/Ile) were studied, significantly increased risk (adjusted OR: 2.69; 95\% CI: 1.39-5.32) was observed in infertile patients when compared with normal controls $(P=0.003)$. However, the frequency of GSTM1 null+GSTP1 (Ile/Val or Val/Val) was nearly equal in cases and control groups (11.4, and $10.2 \%$, respectively; $P=1.0$ ). The risk associated with all the three high-risk GST genotypes compared with no risk genotypes was also investigated (Table 4 ). When the genotypes of GSTM1, GSTT1 and GSTP1 were combined, eight possible combinations were observed. Individuals with combination of the null genotypes of GSTT1, GSTM1 and the wild type (GSTP1 gene) were at significantly higher risk to be infertile when compared with individuals having no high-risk GSTs genotypes (adjusted OR: 4.45; 95\% CI: $1.59-12.24, P=0.002$ ). The combination of other GSTs genotype combinations has not been found to be associated with significant infertility risk (Table 4 ).

\section{Correlation with semen parameters}

The null GSTM1 genotype was strongly negatively correlated with sperm density $(r=-0.68, P=0.004)$, sperm motility $(r=-0.72$, $P=0.003)$ and sperm morphology $(r=-0.78, P=0.001)$. There was also weak but statistically significant inverse correlation between null GSTT1 genotype and sperm density $(r=-0.38, P=0.04)$, sperm

Table 3 Distribution of double GST genotypes among infertile patients and controls

\begin{tabular}{|c|c|c|c|c|c|}
\hline \multicolumn{6}{|l|}{ GSTM1 and GSTT1 } \\
\hline Both present & $102(61.4 \%)$ & 79 (47.6\%) & 1.0 (referent) & & \\
\hline Both null & $14(8.4 \%)$ & $32(19.3 \%)$ & 2.92 & $1.57-5.54$ & 0.0007 \\
\hline \multicolumn{6}{|l|}{ GSTM1 and GSTP1 } \\
\hline $\mathrm{M} 1(-/-)$ and $\mathrm{P} 1(\mathrm{Ile} / \mathrm{lle})$ & $22(13.3 \%)$ & $46(27.7 \%)$ & 2.47 & $1.46-4.17$ & 0.0006 \\
\hline $\mathrm{M} 1(-/-)$ and $\mathrm{P} 1(\mathrm{lle} / \mathrm{Val}$ or $\mathrm{Val} / \mathrm{Val})$ & $24(14.5 \%)$ & $26(15.7 \%)$ & 1.14 & $0.66-1.93$ & 0.78 \\
\hline \multicolumn{6}{|l|}{ GSTT1 and GSTP1 } \\
\hline $\mathrm{T} 1(+/+)$ and $\mathrm{P} 1(\mathrm{lle} / \mathrm{lle})$ & $77(46.4 \%)$ & $72(43.4 \%)$ & 0.92 & $0.65-1.43$ & 0.81 \\
\hline
\end{tabular}

Abbreviations: $\mathrm{Cl}$, confidence interval; GST, glutathione-S-transferase; OR, odds ratio.

Table 4 Distribution of triple GST genotypes among infertile patients and controls

\begin{tabular}{|c|c|c|c|c|c|}
\hline Triple GST genotypes & Control $(\mathrm{N}=166)(\%)$ & Infertile patients $(\mathrm{N}=166)(\%)$ & Odds ratio (OR) & $95 \% \mathrm{Cl}$ & P-value \\
\hline $\mathrm{M} 1$ and $\mathrm{T} 1(+/+)$ and $\mathrm{P} 1(\mathrm{lle} / \mathrm{lle})$ & $57(34.3 \%)$ & $44(26.5 \%)$ & 0.72 & $0.47-1.20$ & 0.16 \\
\hline $\mathrm{M} 1$ and $\mathrm{T} 1(+/+)$ and $\mathrm{P} 1(\mathrm{lle} / \mathrm{Val}$ or $\mathrm{Val} / \mathrm{Val})$ & $46(27.7 \%)$ & $32(19.3 \%)$ & 0.66 & $0.43-1.11$ & 0.12 \\
\hline $\mathrm{M} 1(-/-), \mathrm{T} 1(+/+)$ and $\mathrm{P} 1(\mathrm{lle} / \mathrm{Ile})$ & $17(10.3 \%)$ & $26(15.7 \%)$ & 1.64 & $0.82-2.95$ & 0.11 \\
\hline $\mathrm{M} 1(-/-), \mathrm{T} 1(+/+)$ and $\mathrm{P} 1(\mathrm{Ile} / \mathrm{Val}$ or $\mathrm{Val} / \mathrm{Val})$ & $14(8.4 \%)$ & $14(8.4 \%)$ & 1.01 & $0.46-2.10$ & 1.05 \\
\hline $\mathrm{M} 1(+/+), \mathrm{T} 1(-/-)$ and $\mathrm{P} 1(\mathrm{lle} / \mathrm{Ile})$ & $10(6.0 \%)$ & $13(7.8 \%)$ & 1.45 & $0.65-3.32$ & 0.42 \\
\hline $\mathrm{M} 1(+/+), \mathrm{T} 1(-/-)$ and $\mathrm{P} 1(\mathrm{Ile} / \mathrm{Val}$ or $\mathrm{Val} / \mathrm{Val})$ & $9(5.4 \%)$ & $7(4.2 \%)$ & 0.74 & $0.28-1.84$ & 0.64 \\
\hline $\mathrm{M} 1(-/-), \mathrm{T} 1(-/-)$ and $\mathrm{P} 1(\mathrm{lle} / \mathrm{lle})$ & $4(2.4 \%)$ & $17(10.2 \%)$ & 4.45 & $1.59-12.24$ & 0.002 \\
\hline $\mathrm{M} 1(-/-), \mathrm{T} 1(-/-)$ and $\mathrm{P} 1(\mathrm{lle} / \mathrm{Val}$ or $\mathrm{Val} / \mathrm{Val})$ & $9(5.4 \%)$ & $13(7.8 \%)$ & 1.12 & $0.50-2.42$ & 0.81 \\
\hline
\end{tabular}

Abbreviations: $\mathrm{Cl}$, confidence interval; GST, glutathione-S-transferase; OR, odds ratio. 
motility $(r=-0.34, P=0.04)$ and sperm morphology $(r=-0.42$, $P=0.03)$. As well a strong negative correlation existed between GSTP1 (Ile/Ile) polymorphism and sperm density $(r=-0.56$, $P=0.02)$, sperm motility $(r=-0.54, P=0.03)$ and sperm morphology $(r=-0.62, P=0.01)$.

\section{DISCUSSION}

This study is the first report on the association between GSTM1, GSTT1 and GSTP1 polymorphisms and susceptibility to infertility in the Iranian population. This study investigated GSTM1, GSTT1 and GSTP1 gene polymorphisms in Iranian subjects and showed that the frequency of GSTM1, GSTT1 and GSTP1 (Ile/Val) genotypes was significantly higher in a normal population than in infertile subjects, whereas the frequency of GSTM1 null, GSTT1 null and GSTP1 (Ile/ Ile) in infertile patients was significantly higher as compared with normal controls. The frequency of GSTM1 null genotype ranges from 42 to $60 \%$ in Europeans, $42-54 \%$ in Asians and $16-36 \%$ in Africans; and for GSTT1 null genotype, the reported frequencies are 13-26\% and $35-52 \%$ in Caucasians and Asians, respectively. ${ }^{28}$ This study revealed that in normal controls the frequency of GSTM1 null genotype was $27.7 \%$, the frequency of GSTT1 null genotype was $19.3 \%$ and the frequencies of GSTP1-Ile/Ile, -Ile/Val and -Val/Val genotypes were $51.8,45.8$ and $2.4 \%$, respectively. The distribution of GSTP1 genotypes followed Hardy-Weinberg equilibrium. Such marked ethnic differences may have important clinical and health implications. Different ethnic groups may have different exposure and susceptibility to environmental factor-induced diseases such as infertility due to distinct GST gene polymorphism. Gene-environment interaction between GSTM1 and air pollution has been reported by Rubes et al. ${ }^{16}$ In the available literature, we could not find similar studies from Iranian population for comparison.

The increase in frequency of GSTM1 null, and GSTT1 null genotypes among infertile patients when compared with the controls has indicated that GSTM1 and GSTT1 polymorphisms are associated with an increase in infertility risk. Wu et al. ${ }^{24}$ believe that GSTT1 null genotype predisposes to over oxidative damage to spermatocytes of infertile patients with varicocele. Similar increase in risk for infertility was also reported in Turkish ${ }^{11}$ and Brazilian populations. ${ }^{10}$ Finotti et al. ${ }^{10}$ examined GSTM1 and GSTT1 polymorphism in 233 Brazilian men with idiopathic infertility. They found that individuals polymorphic for GSTM1 and GSTT1 genotypes are susceptible to decrease in sperm quality and infertility. However, one study in Russian men with idiopathic infertility reported an increase in risk for infertility with nondeletion genotype of the GSTT1 gene. ${ }^{23}$ Also, there are two case-control studies in which the role of GSTT1, GSTM1 genotypes in male infertility has been addressed in patients with varicocele. ${ }^{29,30}$ Okubo et al. ${ }^{29}$ concluded that the response rate to varicocelectomy is significantly better in patients with the GSTT1 genotype than the GSTT1-null genotype. In the second study, Chen et al. ${ }^{30}$ showed that GST M1-genotype predisposes to increased oxidative damage to sperm of patients with varicocele. Such discrepancy could be explained by a different study population, different analytical methods, study sample sizes, effect of other genes and/or genotypes or a different study design. Glutathione transferases involve in the metabolic pathways of both methylation and transulfuration. ${ }^{31}$ This could be another explanation for these discrepancies. Methylenetetrahydrofolate reductase is a gene involved in the process of DNA synthesis and methylation. ${ }^{32}$ Subjects carrying the homozygous variant methylenetetrahydrofolate reductase genotype and of a functional copy of GSTM1 has a significantly higher risk of infertility. Such a risk becomes non-significant when the GSTM1 deletion is also present. ${ }^{31}$ In our study, all of the infertile patients had abnormal sperm parameters in all three domains (density, motility and morphology).

The importance of oxidative stress in spermatogenesis has recently received increasing attention. Human studies have generally supported the hypothesis that impaired spermatogenesis is associated with increased seminal plasma oxidative stress. ${ }^{32,33}$ Under pathological circumstances, ROS production exceeds the seminal plasma antioxidant capacity and causes increased oxidative stress. ${ }^{34}$ GST a multigene family of phase II detoxification enzymes, acts as an antioxidant through inactivation of endogenous unsaturated epoxides, aldehydes, hydroperoxides and quinines, formed as secondary metabolites during the oxidative stress, thus having a key role in protecting cells against oxidative damage. $^{35}$

Taken together, our findings suggested that a genetic background (GST gene polymorphisms) may contribute to the development of infertility. The most likely explanation is based on the strong antioxidant activity of GST enzyme against the damaging effects of oxidative stress. GSTM1 and GSTT1 polymorphisms cause disparities on enzyme activities that can also result in oxidative stress potentiation $^{36}$ through changes on GSH metabolism. Individuals with GSTM1 null, and GSTT1 null have complete absence of activity of these genes. ${ }^{37}$ The patients carrying the risk genotypes of GSTM1 null, and GSTT1 null simultaneously could be subjected to increased oxidative stress, which may account for the increase in risk to be infertile. Similarly several fold increased risk in the infertile patients with the combination of null genotypes of GSTT1, GSTM1 and the wild type (GSTP1 gene) could be attributed to the increased accumulation of ROS, because excessive ROS may not be detoxified due to deletion or variant genotype of GSTs.

Our study has several limitations. We did not include in our analysis the completed information about the familial history of infertility. Another limitation of the study is the low power $(80 \%)$ of the study for gene-gene interactions and stratified analyses. Therefore the probability of chance findings in these analyses should be considered. As a result, it is worthwhile to design multi-center study to collect data on large numbers of cases for such analysis.

\section{CONCLUSIONS}

In conclusion, our findings suggest that GST gene polymorphism is associated with an increased probability of infertility. Risk to infertility was further found to increase in subjects carrying the combination of null or variant genotypes of GSTs. Also, several fold increased risk in the infertile cases carrying combinations of risk genotype of GSTs implies that interaction between the genes involved in detoxifying ROS may be important in detecting the susceptibility to infertility. Further studies should be done on a larger scale and different ethnic background for confirmation of our results.

\section{CONFLICT OF INTEREST}

The authors declare no conflict of interest.

\section{ACKNOWLEDGEMENTS}

We are indebted to the staff and volunteer participants for their close cooperation and important contributions. We thank Miss Saba Safarinejad for statistical analysis.

1 Boivin, J., Bunting, L., Collins, J. A. \& Nygren, K. G. International estimates of infertility prevalence and treatment-seeking: potential need and demand for infertility medical care. Hum. Reprod. 22, 1506-1512 (2007). 
2 Safarinejad, M. R. Infertility among couples in a population-based study in Iran: prevalence and associated risk factors. Int. J. Androl. 31, 303-314 (2008).

3 Pasqualotto, F. F., Pasqualotto, E. B., Sobreiro, B. P., Hallak, J., Medeiros, F. \& Lucon, A. M. Clinical diagnosis in men undergoing infertility investigation in a university hospital. Urol. Int. 76, 122-125 (2006).

4 Comhaire, F. H., Mahmoud, A. M. A. \& Schoonjans, F. Sperm quality, birth rates and the environment in Flanders (Belgium). Reprod. Toxicol. 23, 133-137 (2007).

5 Carlsen, E. L., Giwercmn, A. \& Keiding, N. Evidence for decreasing quality of semen during past 50 years. Br. Med. J. 305, 609-613 (1992).

6 Wong, W. Y., Thomas, C. M., Merkus, J. M., Zielhuis, G. A. \& Steegers-Theunissen, R. P. Male factor subfertility: possible causes and the impact of nutritional factors. Fertil. Steril. 73, 435-442 (2000).

7 Skakkeback, N. E., Giwereman, A. \& de Kvetser, D. Pathogenesis and management of male infertility. Lancet 343, 1473-1479 (1994).

8 Rybar, R., Markova, P., Veznik, Z., Faldikova, L., Kunetkova, M., Zajicova, A. et al. Sperm chromatin integrity in young men with no experiences of infertility and men from idiopathic infertility couples. Andrologia 41, 141-149 (2009).

9 O'Flynn O'Brien, K. L., Varghese, A. C. \& Agarwal, A. The genetic causes of male factor infertility: a review. Fertil. Steril. 93, 1-12 (2010).

10 Finotti, A. C., Costa E Silva, R. C., Bordin, B. M., Silva, C. T. \& Moura, K. K. Glutathione S-transferase M1 and T1 polymorphism in men with idiopathic infertility. Genet. Mol. Res. 8, 1093-1098 (2009).

11 Aydos, S. E., Taspinar, M., Sunguroglu, A. \& Aydos, K. Association of CYP1A1 and glutathione S-transferase polymorphisms with male factor infertility. Fertil. Steril. 92, 541-547 (2009).

12 Saleh, R. A. \& Agarwal, A. Oxidative stress and male infertility: from research bench to clinical practice. J. Androl. 23, 737-752 (2002).

13 Ketterer, B. A bird's eye view of the glutathione transferase field. Chem. Biol. Interact. 138, 27-42 (2001).

14 Dusinská, M., Ficek, A., Horská, A., Raslová, K., Petrovská, H., Vallová, B. et al. Glutathione S-transferase polymorphisms influence the level of oxidative DNA damage and antioxidant protection in humans. Mutat. Res. 482, 47-55 (2001).

15 Ryberg, D., Skaug, V., Hewer, A., Phillips, D. H., Harries, L. W., Wolf, C. R. et al. Genotypes of glutathione transferaseMland $\mathrm{P} 1$ and their significance for lung DNA adduct levels and cancer risk. Carcinogenesis 18, 1285-1289 (1997).

16 Rubes, J., Selevan, S. G., Sram, R. J., Evenson, D. P. \& Perreault, S. D. GSTM1 genotype influences the susceptibility of men to sperm DNA damage associated with exposure to air pollution. Mutat. Res. 625, 20-28 (2007).

17 Lo, H. W. \& Ali-Osman, F. Genetic polymorphism and function of glutathione S-transferases in tumor drug resistance. Curr. Opin. Pharmacol. 7, 367-374 (2007).

18 Strange, R. C., Spiteri, M. A., Ramachandran, S. \& Fryer, A. A. Glutathione-Stransferase family of enzymes. Mutat. Res. 482, 21-26 (2001).

19 Jiang, S., Yu, L., Cheng, J., Leng, S., Dai, Y., Zhang, Y. et al. Genomic damages in peripheral blood lymphocytes and association with polymorphisms of three glutathione S-transferases in workers exposed to formaldehyde. Mutat. Res. 695, 9-15 (2010).

20 Pemble, S., Schroeder, K. R., Spencer, S. R., Meyer, D. J., Hallier, E., Bolt, H. M. et al. Human glutathione S-transferase Theta (GSTT1): cDNA cloning and the characterization of a genetic polymorphism. Biochem. J. 300, 271-276 (1994).

21 Osman, F. A., Akande, O., Antoun, G., Mao, L. X. \& Buolamwin, J. Molecular cloning characterization, and expression in Escherichia coli of full-length cDNAs of three human glutathione S-transferase $\mathrm{Pi}$ gene variants, evidence for different catalytic activity of the encoded proteins. J Biol Chem 272, 10004-10012 (1997).

22 Aydemir, B., Onaran, I., Kizile, A. R. Alici, B. \& Akyolcu, M. C. Increased oxidative damage of sperm and seminal plasma in men with idiopathic infertility is higher in patients with glutathione S-transferase Mu-1 null genotype. Asian J. Androl. 9, 108-115 (2007).

23 Polonikov, A. V., Yarosh, S. L., Kokhtenko, E. V., Starodubova, N. I., Pakhomov, S. P. \& Orlova, V. S. The functional genotype of glutathione S-transferase T1 gene is strongly associated with increased risk of idiopathic infertility in Russian men. Fertil. Steril (2010). e-pub ahead of print.

24 Wu, Q., Xing, J., Xue, W., Sun, J., Wang, X. \& Jin, X. Influence of polymorphism of glutathione $S$-transferase T1 on Chinese infertile patients with varicocele. Fertil. Steril. 91, 960-962 (2009).

25 Wu, Q. F., Xing, J. P., Tang, K. F., Xue, W., Liu, M., Sun, J. H. et al. Genetic polymorphism of glutathione S-transferase $\mathrm{T} 1$ gene and susceptibility to idiopathic azoospermia or oligospermia in northwestern China. Asian J. Androl. 10, 266-270 (2008).

26 WHO. World Health Organization Laboratory Manual for the Examination of Human Semen and Sperm-Cervical Mucus Interaction. (Cambridge University Press, Cambridge, UK, 1999).

27 Liu, Y. J., Huang, P. L., Chang, Y. F., Chen, Y. H., Chiou, Y. H., Xu, Z. L. et al. GSTP1 genetic polymorphism is associated with a higher risk of DNA damage in pesticideexposed fruit growers. Cance. Epidemiol. Biomarkers Prev. 15, 659-666 (2006).

28 Hatagima, A., Costa, E. C. B., Marques, C. F. S., Koifman, R. J., Boffetta, P. \& Koifman, S. Glutathione S-transferase polymorphisms and oral cancer: A case-control study in Rio de Janeiro, Brazil. Oral. Oncol. 44, 200-207 (2008).

29 Okubo, K., Nagahama, K., Kamoto, T., Okuno, H., Ogawa, O. \& Nishiyama, H. GSTT1 and GSTM 1 polymorphisms are associated with improvement in seminal findings after varicocelectomy. Fertil. Steril. 83, 1579-1580 (2005).

30 Chen, S. S., Chang, L. S., Chen, H. W. \& Wei, Y. H. Polymorphisms of glutathione Stransferase M1 and male infertility in Taiwanese patients with varicocele. Hum. Reprod. 17, 718-725 (2002).

31 Paracchini, V., Garte, S. \& Taioli, E. MTHFR C677T polymorphism, GSTM1 deletion and male infertility: a possible suggestion of a gene-gene interaction? Biomarkers 11, 53-60 (2006).

32 Pasqualotto, F. F., Sharma, R. K., Nelson, D. R., Thomas, A. J. \& Agarwal, A. Relationship between oxidative stress, semen characteristics and clinical diagnosis in men undergoing infertility investigation. Fertil. Steril. 73, 459-464 (2000).

33 Agarwal, A. \& Said, T. M. Oxidative stress, DNA damage and apoptosis in male infertility: a clinical approach. BJU. Int. 95, 503-507 (2005).

34 Naughton, C. K., Nangia, A. K. \& Agarwal, A. Pathophysiology of varicoceles in male infertility. Hum. Reprod. Update. 7, 473-481 (2001).

35 Sharma, R., Yang, Y., Sharma, A., Awasthi, S. \& Awasthi, Y. C. Antioxidant role of glutathione S-transferases: protection against oxidant toxicity and regulation of stressmediated apoptosis. Antioxid Redox Signal 6, 289-300 (2004).

36 Hayes, J. D. \& Strange, R. C. Glutathione S-transferase polymorphisms and their biological consequences. Pharmacology 61, 154-166 (2000).

37 Beeghly, A., Katsaros, D., Chen, H., Fracchioli, S., Zhang, Y., Massobrio, M. et al. Glutathione S-transferase polymorphisms and ovarian cancer treatment and survival. Gynecol. Oncol. 100, 330-337 (2006). 